\title{
Towards a global list of accepted species III. Independence and stakeholder inclusion
}

\author{
Stijn Conix ${ }^{1}$ (D) - Stephen T. Garnett ${ }^{2}$ (D) - Kevin R. Thiele ${ }^{3}$ (D) - Les Christidis ${ }^{4}$ (D) - Peter Paul van Dijk ${ }^{5}$ (D) \\ Olaf S. Bánki ${ }^{6,7}$ (D) Saroj K. Barik ${ }^{8}$. John S. Buckeridge ${ }^{9,10}$ - Mark J. Costello ${ }^{11,12}$ (D) Donald Hobern ${ }^{13}$ (D) \\ Paul M. Kirk ${ }^{14}$ (D) - Aaron Lien ${ }^{15}$ (D) - Svetlana Nikolaeva ${ }^{16,17,18} \cdot$ Richard L. Pyle ${ }^{19}$ (D) - Scott A. Thomson ${ }^{20}$ (D) \\ Zhi-Qiang Zhang ${ }^{21,22}$ (D) Frank E. Zachos ${ }^{23,24,25}$
}

Received: 19 January 2021 / Accepted: 18 May 2021 / Published online: 13 July 2021

(C) Gesellschaft für Biologische Systematik 2021

\begin{abstract}
A global consensus list of the world's species must be based on the best available taxonomic research, and its contents should not be biased towards certain political or social aims. At the same time, users of any global list must be involved or consulted in its establishment to ensure that the list meets their needs. This paper argues that while these two desiderata - independence and inclusion-might seem to be in conflict, they are in fact compatible. More precisely, it suggests the roles taxonomists and users could play in establishing and maintaining a global consensus list to make sure that this list is both inclusive and independent.
\end{abstract}

Keywords Taxonomic list · Independence of science $\cdot$ Freedom of science $\cdot$ Values in science $\cdot$ Users of taxonomy

This article is part of the Special Issue and Topical Collection Towards a global list of accepted species

Stijn Conix

stijn.conix@kuleuven.be

1 Centre for Logic and Philosophy of Science, KU Leuven, Leuven, Belgium

2 Research Institute for the Environment and Livelihoods, Charles Darwin University, Northern Territory 0909, Australia

3 Taxonomy Australia, Australian Academy of Science, Canberra, Australia

4 Southern Cross University, Coffs Harbour, New South Wales 2450, Australia

5 Global Wildlife Conservation, Austin, Texas, USA

6 Species 2000, Leiden, the Netherlands

7 Naturalis Biodiversity Center, Leiden, the Netherlands

8 CSIR-National Botanical Research Institute, Rana Pratap Marg, Lucknow, India

9 Earth \& Oceanic Systems Group, RMIT, Melbourne, Australia

10 Museums Victoria, Carlton 3001, Australia

11 University of Auckland, Auckland, New Zealand

12 Faculty of Biosciences and Aquaculture, Nord University, Bodø, Norway
13 Species 2000, Canberra, Australia

14 Royal Botanic Garden, Kew, Richmond, Surrey, UK

15 School of Natural Resources and the Environment, University of Arizona, Tucson, Arizona, USA

16 Department of Earth Sciences, The Natural History Museum, London, UK

17 Borissiak Paleontological Institute, Russian Academy of Science, Moscow, Russia

18 Kazan State University, Kazan, Russia

19 Bernice Pauahi Bishop Museum, 1525 Bernice Street, Honolulu, Hawai, USA

20 Chelonian Research Institute, Oviedo, Florida, USA

21 Manaaki Whenua-Landcare Research Auckland, Auckland, New Zealand

22 School of Biological Sciences, The University of Auckland, Auckland, New Zealand

23 Natural History Museum Vienna, Vienna, Austria

24 Department of Evolutionary Biology, University of Vienna, Vienna, Austria

25 Department of Genetics, University of the Free State, Bloemfontein, South Africa 


\section{Introduction}

Taxonomy is one of the fundamental disciplines in biology with many other disciplines relying on taxonomic classifications. Taxonomists create a map of patterns of variation in biodiversity (species and other taxa) that other biologists rely on to navigate the complexity of life on Earth. While there may well be multiple good ways of mapping biodiversity (Conix, 2018), the particular map created by taxonomists is very influential because it is commonly used by scientists and non-scientists. Taxonomy's map of the organic world is conveyed to these users of taxonomy in forms such as phylogenetic trees, identifications keys, and lists of accepted taxa. Among these, taxonomic lists are particularly influential as they are commonly used by policy-makers both on the national (e.g., conservation legislation) and international (e.g. multilateral environmental agreements) levels. However, while over 2 decades of effort to list the world's species have resulted in excellent and largely comprehensive lists (e.g. Catalogue of Life $(\mathrm{CoL}))$ and taxon-specific or ecosystem-specific lists (e.g. the World Register of Marine Species (WoRMS)), no single global list is generally accepted by scientists and key users. This lack of consensus sometimes forces list users to choose between multiple competing lists, which has farreaching negative consequences (Garnett et al., 2020).

In a call to resolve this problem by improved governance of taxonomic lists, a recent paper (Garnett \& Christidis, 2017) triggered a debate that has resulted in the formation of a Working Group on the Governance of Taxonomic Lists under the auspices of the International Union of Biological Sciences (IUBS). This working group has proposed a set of principles for the governance of taxonomic lists, and aims to collaborate with existing global listing initiatives on governance mechanisms that help build consensus among scientists and key users about a single global list of the world's accepted species (or, more generally, 'taxa', depending on which ranks would be included in such a list). ${ }^{1}$

Two of the ten general principles proposed for creating a single global list (Garnett et al., 2020) are that 'the species list must be based on science and free from non-taxonomic considerations and interference' and 'governance of the species list must aim for community support and use'. The first principle acknowledges that widespread acceptance of a global list will only occur if it is demonstrably scientifically sound; i.e. the list is based on the results of the best available taxonomic research. For that to be true, political, social, commercial, or other non-taxonomic preferences of list users should have no part in taxonomic decisions about which taxa meet scientific criteria for inclusion on an authoritative list. The second

\footnotetext{
${ }^{1}$ Note that the aim is not necessarily to have all taxonomists agree on all taxa. Rather, the aim is to build consensus about which taxa to accept on the list, even if not everyone agrees with every single included taxon.
}

principle aims to ensure the list aids users of taxonomy in improving the efficiency and consistency of decisionmaking that relies on taxonomy. The authority of any global list will be derived at least in part from its actual adoption by users of taxonomy, and users are unlikely to endorse a list unless they have a role in establishing and maintaining it.

While these two principles are self-evident when considered separately, they may appear incompatible when taken together. How can an authoritative list of species be independent from non-taxonomic considerations if (non-taxonomist) users of the list have to be involved in its establishment? ${ }^{2}$ As it is, this tension is neither new nor unique. Taxonomic judgment has long had implications for conservation, trade, and development (see Box 1 for a non-exhaustive list of users of taxonomy), and some authors have pointed to non-taxonomic influences on species classification (Harris \& Froufe, 2005; Isaac et al., 2004; Karl \& Bowen, 1999). More broadly, tensions between independence and stakeholder influence are characteristic of 'boundary organizations', formal bodies that govern the interaction and facilitate productive relations and communication between science and policy (Guston, 2001; Miller, 2001). Such tensions must therefore be expected in any governance structure that might oversee a global species list. Exactly the same sort of tension between inclusion and independence is illustrated clearly by what is perhaps the most influential and well-studied example of such an organization, namely, the Intergovernmental Panel on Climate Change (Hulme \& Mahony, 2010).

Box 1 A non-exhaustive list of some of the main scientific and nonscientific users of taxonomy and species lists

Science

Taxonomy

Ecology

Conservation science

Bioinformatics

Evolutionary biology
Most taxonomies are built by refining pre-existing taxonomies, and new species can only be recognized on the basis of a clear understanding of species already recognized

Species often serve as the units of patterns and processes studies in macro-ecology (Isaac et al., 2004)

Understanding and implementing conservation relies crucially on an inventory of what is to be conserved. Taxonomic categories are the most popular way of 'mapping', measuring and prioritising biodiversity attributes (Diniz-Filho et al., 2013)

Taxonomic classifications serve as the backbone for integrating information from different sources in databases (GBIF Secretariat, 2019)

\footnotetext{
${ }^{2}$ Both taxonomists and non-taxonomists are important users of lists of accepted species. For convenience, the term 'user' hereafter will refer only to nontaxonomist users
} 
Species and other taxa serve as the units in macro-evolutionary studies.

Palaeontology and geology

Climate Science

Non-Science

Human health

Conservation

Trade regulation

Biosecurity

Industry, agriculture and wealth generation

Judiciary and law enforcement

Lists of fossil taxa play a crucial role in region (e.g. Buckeridge et al., 2018)

Taxonomy contributes to knowledge about (changes in) the distribution of species, which is crucial for predicting, monitoring, and understanding climate change and its consequences (e.g. Hickling et al., 2006; Root et al., 2003) regulating trade in medicinal taxa, and discovering new resources through bioprospecting (e.g. Dias et al., 2012; Harvey, 2008) conservation action (e.g. protecting rare species or combating invasive species) and figure in conservation laws and agreements (Mace, 2004). Taxon richness, diversity, and uniqueness at particular sites often guide conservation investment

Taxonomic categories figure in agreements and laws about the trade of organic materials, products, and protected organisms

Taxonomists play a crucial role in threat to food security biological resources such as crop wild relatives, genes for new crop varieties,

Biodiversity protective regulations, (commercial and recreational) hunting reconstructing the geological history of a

Taxonomy is required for identifying disease organisms and their hosts and vectors, for

Taxonomic categories are often the target of identifying and managing pests that pose a

Taxonomy is important for discovering new new products in biotechnology, and new models for biomimicry (Bull et al., 2000) and fishing management, and trade regulation are normally enacted through explicit listings of species and higher taxon names, and their implementation depends on accurate identification of specimens

Social scientific studies of such boundary organizations have indeed shown how difficult it is to be policy-neutral and policyrelevant. What emerges from these studies is that the intuitively appealing 'linear model', in which scientists simply provide information for governments to use, rarely works (Young et al., 2014). Instead, successful science-policy boundary organizations typically rely on an interactive model with one role for scientists and another role for policy-makers and other users (Young et al., 2014). The key to making such a model work without violating either of the aforementioned principles is for roles to be clearly and transparently defined in advance (Rothman et al., 2009). Taking this as its starting point, the aim of this paper is to define the roles of taxonomists and users in setting up the governance structure for an authoritative list of accepted species, and to show that this can be done in a way that meets both Principle 1 (the list must be independent and based on science) and Principle 2 (users must be involved in setting up the list).

\section{Value-laden decision-points in creating a list of the world's species}

The governance structure that we propose for establishing and maintaining an authoritative list of accepted species consists of a body to endorse the listing processes used by taxonomists to develop lists of accepted species in specific taxonomic groups - call this body the 'endorsement body'. By 'listing process', we mean the mechanisms, rules, and procedures used and chosen to create a list of accepted species of a particular taxonomic group. The lists produced by endorsed listing processes are then combined and in aggregate make up the global authoritative species list. Thus, the endorsement body does not consider the detail of the particular lists of various taxonomic communities, but rather evaluates the processes these communities have adopted to compile their lists. The overall process of coming to the endorsement of a single consensus list is what we will call the 'global listing process' (Lien et al., 2021).

To clarify the roles of taxonomists and users in the global listing process, it is useful to introduce a distinction between two broad kinds of decision that are part of this process. On the one hand, there are decisions that can be settled on what might be called 'purely taxonomic grounds', i.e. empirical evidence, broadly accepted biological theories and models, and epistemic standards such as empirical adequacy, accuracy, predictive power, and precision. Examples of decisions that are more or less fully determined by such taxonomic considerations include which primers to use for amplifying DNA, which analytical tools to use on morphometric data, and which methods to use to infer phylogenetic relationships. In the remainder of the paper, we will refer to these as 'purely taxonomic' decisions, and to the grounds for making them as 'purely taxonomic'. On the other hand, there are some decisions in the global listing process that cannot be settled on purely taxonomic grounds. These decisions thus require other factors to ground them-we will call such factors 'values', and such decisions 'value-laden'.

\footnotetext{
${ }^{3}$ Note that we are not claiming that there is always a clear boundary between such value-laden and purely taxonomic decisions, or between the kinds of factors that might play a role in making them (so-called epistemic and nonepistemic values) (Rooney, 1992). Rather, we believe there is a continuum with clear cases on both ends. As the cases in taxonomy are often outside the boundary area (e.g. seeking financial gains is an uncontroversial value-laden motive), we will for the sake of clarity assume the distinction between epistemic and non-epistemic factors in the remainder of the paper.
} 
If all decisions required for setting up the global listing process were purely taxonomic, then assigning roles would be straightforward. Only taxonomists - used in a broad sense that includes both amateurs and professionals involved in describing new species or in other aspects of taxonomy such as phylogeny and classification (Costello, 2020) - would have to be involved. As we explain below, this is not the case: the global listing process includes decisions that are not fully determined by purely taxonomic grounds. This means that setting up a global listing process requires value judgments. And while it is obvious that only taxonomists should be responsible for purely taxonomic decisions, value-laden decisions are less straightforward. Thus, to clarify the roles taxonomists and users should play in the development of a consensus list of accepted species, it is useful to start by identifying the various value-laden decisions in this process.

In the global listing process we propose, there are three types of decision that are partly or fully value-laden: conceptual decisions; decisions about evidentiary standards; and decisions about governance structures. We discuss each of these types of value-laden decisions separately, and suggest who (taxonomists or users) should play a role in making them. We then discuss in the next section the roles taxonomists and users should play in each of these decisions, and how they should do this.

\section{No fact of the matter}

Speciation, and evolutionary change more generally, is usually a gradual process with the extent of difference between lineages occurring along a continuum. Classification, on the other hand, is a binary process: a given group of organisms or populations may be recognized as a species, or as not-a-species, but it cannot be classified as, e.g. 'a half-species'. As a consequence, it is sometimes difficult to fit evolutionary lineages into the binary categories available in a taxonomic list, namely, groups recognized as taxa (e.g. species) and groups not recognized as taxa at the same level (Zachos et al., 2020). This is particularly the case for recently diverged lineages, which are often independent in some ways but not in others, and for which it may be unclear whether they will remain independent. In such cases, the decisions required for drawing taxonomic boundaries are not fully determined by purely taxonomic considerations, so value judgments have to be exercised (Thiele et al., n.d., this issue). For example, two species may be morphologically, genetically, and geographically distinct, but their populations may produce fertile hybrids should they come into contact (e.g. in captivity or through species introductions). To make such decisions, taxonomists often choose a particular species concept or follow a certain tradition. Some taxonomists may adopt a species concept such that only highly independent lineages should be listed as species, while others may argue with equal merit that recently diverged lineages should be listed as species even when their evolutionary trajectories are not yet fully independent (De Queiroz, 2005; Zachos, 2016).

In such cases, we cannot simply look at the facts to make the decision - that is, there is no fact of the matter about the particular rank of the group in question. Purely taxonomic grounds do not determine whether a population is recognized as a species, a subspecies, or as part of another species, and the problem cannot be resolved simply by collecting more evidence (see Kottelat, 1997 for an example). There is no time to see how the lineage resolves the question itself in the future as that may take thousands or even millions of years - a decision is needed right now on whether the taxon should be listed as a species. We argue that such decisions should be made by taxonomists, and we explain below on what grounds they could make them. It is important that only taxonomists make these value judgments, because these judgments directly influence which species are listed. Allowing users to influence these decisions would provide them with the opportunity - clearly in violation of the independence principle - to determine the content of species lists in line with an external agenda.

By confining such 'no fact of the matter' judgements to the domain of taxonomists, we do not mean to imply that taxonomists are not vulnerable to extra-taxonomic considerations. Indeed, many taxonomists are deeply concerned about valueladen issues such as conservation, and consideration of these issues may be important motivations for taxonomists to pursue their career. It may even be that taxonomists occasionally let value judgements influence their taxonomic decisions (Harris \& Froufe, 2005; Isaac et al., 2004; Karl \& Bowen, 1999). But we argue that 'no fact of the matter' decisions should be made only by taxonomists because these decisions require taxonomic expertise. This is because dealing with difficult cases in taxonomy is rarely as simple as finding out that there is no fact of the matter and then using value-judgements to choose a rank. Instead, evaluation in these cases often partially depends on the kinds of evidence that have been collected, the models used for analysis, and other methodological decisions. These methodological decisions are, in turn, typically motivated by prior conceptual decisions. For example, a taxonomist who prefers the Biological Species Concept is more likely to collect evidence that reveals patterns of interbreeding than another taxonomist who prefers the Morphological Species Concept (Frankham et al., 2012). Because substantial taxonomic expertise is needed for identifying, understanding, and arbitrating cases where there is no fact of the matter, taxonomists are in the best position to do this.

Because taxonomists do not work in a vacuum closed off from societal and extra-scientific interests, it is important that in making such 'no fact of the matter' value-judgements, they consciously strive not to let particular usages of the list influence their decision. We discuss below how such valuejudgements could be made without attuning them to particular 
list users. In addition, the governance mechanisms within taxonomic communities can help avoid parochial interests having an undue influence (Pyle et al., 2021). For example, we propose that listing processes should be as inclusive as possible with respect to the relevant taxonomic community and that the reasoning underlying the value-judgements is transparently articulated. This allows various forms of peer review to act as a filter for unjustified extra-taxonomic influences.

\section{Uncertainty}

Even if we assume that species are being described at a fast rate by the taxonomic workforce (Costello et al., 2013), it is clear that we will be discovering new species for a long time to come. Moreover, many currently accepted species were described long ago on the basis of very imperfect evidence, and some of these will require new research to meet the same evidentiary standards as more recently described species. As the burden of proof for revisions rests with contemporary taxonomists, such new research may require substantial time and resources (Senn et al., 2014). Particularly in cases of species divergence under complex circumstances, delimitation of new species requires extensive research that combines multiple lines of evidence (SchlickSteiner et al., 2010). Thus, even if there is little uncertainty for many (perhaps most) species, it is sometimes impossible to collect sufficient evidence to establish a species beyond reasonable doubt. This means that some species decisions, and hence species lists, inevitably face some levels of uncertainty, even beyond the 'no fact of the matter' argument made in the preceding section.

This inevitable uncertainty is relevant here because it implies that, for any listing decision, it needs to be decided how certain we have to be to make it. In some scientific disciplines, there are broadly used conventional standards to balance false positives and false negatives, like the most widespread statistical significance level of 0.05 . However, there are no such broadly used standards in taxonomy. As the required degree of certainty is also not determined on purely taxonomic grounds, this means that values are needed for doing this (Douglas, 2000, 2009). Value judgments thus play a role in the listing process by setting evidentiary standards. Note that in this role, values only affect the degree of certainty required for listing decisions, and never the content of these decisions. Take, for example, the infamous case of the group of organisms included under the concept of California gnatcatcher (Polioptila californica) (Zink et al., 2000). The status of this group of organisms has long been heavily contested because its habitat — coastal sage scrub in southern California - is of high economic value for real estate development. Depending on whether the gnatcatcher is recognized as a distinct taxon (subspecies), it could be protected and make new real estate projects in its habitat impossible. The point here is that the financial gains and conservation preferences here would not be relevant for deciding whether the group constitutes a valid subspecies. Rather, value judgments would determine how certain we have to be before accepting whether the taxon is listed or not.

The lack of widely used evidentiary standards in taxonomy means that the quality of evidence required for accepting or rejecting a taxon can be adjusted according to the potential consequences of taxonomic error. ${ }^{4}$ For example, it may be reasonable to use less strict standards when nothing consequential hinges on listing the species under consideration. This way, non-charismatic and rarely studied groups that have already been listed on the basis of thin evidence can be listed until, perhaps, new research is done. Conversely, it may be reasonable to set stricter evidentiary requirements for accepting or rejecting a species on the list if errors are costly. For example, if the authorities decide to follow the list in the case of the gnatcatcher, erroneous rejection might lead to extinction of the taxon, while erroneous acceptance might lead to substantial loss of economic opportunity.

In theory, the value judgments described in this subsection ('uncertainty') and the previous ('no fact of the matter') are distinct. Value judgments about evidentiary standards never push for or against listing a particular species. Rather, they help estimate the costs (for societies, economies, and conservation) of taxonomic errors. Values thus do not decide whether a species is recognized, but rather how certain we have to be about changing the status quo about species listing decisions. In cases where there is no fact of the matter, on the other hand, value judgments do co-determine the rank and recognition of a group of organisms and whether it should be listed. In practice, however, these two types of value-laden decisions are hard to distinguish, as listing decisions often involve both substantial uncertainty and conceptual decisions.

Taxonomists have most experience with uncertainty in species delimitation and the ways it can be dealt with. Hence, they are also in a good position to evaluate evidentiary standards for listing. In addition, users of taxonomy could help set evidentiary standards too. In the case of the California gnatcatcher, for example, more evidence than usual was collected precisely because the decision to be made had potentially far-reaching consequences. More broadly, users of taxonomy can alert taxonomists of the consequences of a taxonomic proposal, and thus of the costs associated with the decision to accept or reject it. The taxonomists involved can then adjust the evidence levels required for a decision to the differential costs of both classes of error.

\section{The governance structure of the list}

We propose a global listing process in which an endorsement body endorses the lists of particular taxonomic groups compiled by the communities of taxonomists who study those taxa.

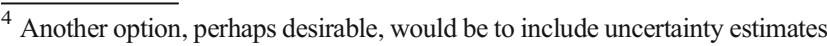
in a global species list. However, such estimates are most likely not available for many species. In addition, even such uncertainty estimates do not eliminate the role of value-judgements described here (John, 2015; Steele, 2012).
} 
The basis of such endorsement would consist in a set of core principles (Garnett et al., 2020) and criteria of adequacy for species lists (Lien et al., 2021). Taxonomic communities with a governance structure that meets the criteria of adequacy are then eligible to provide the endorsement body with a species list. If multiple communities offer lists of the same groups of organisms, the endorsement body has to arbitrate between these lists on the basis of the core principles and criteria of adequacy. For example, one list may be preferred over another if it has better dispute resolution mechanisms or represents more of the active taxonomists working on these organisms. These criteria of adequacy and core principles are a third factor in the global listing process in which value-judgements are inevitably needed. More precisely, there are at least three sets of value-laden decisions required to establish these governmental structures.

First, the basic principles of the endorsement body are not determined by purely taxonomic considerations. They include basic considerations of science and governance such as transparency, independence, fair recognition of listing efforts, stability, respect for scientific freedom, and consistency (Garnett et al., 2020). Both taxonomists and users can legitimately help determine these principles and their application. In fact, the principles as they are currently proposed are the result of discussion among taxonomists, users of taxonomy, and specialists from other fields such as biodiversity informatics and political science. If the principles have to be adapted once the governance structure is running, taxonomists, users, and relevant experts from other fields should again be consulted.

Second, the conditions of adequacy for listing processes are also not determined by taxonomic considerations. These may include considerations such as inclusivity and exclusivity, transparency in appeal and decision-making, peer review, conflict resolution mechanisms, and the degree of consensus achieved (Lien et al., 2021). Again, we hold that both taxonomists and users can contribute to designing criteria of adequacy and ways of implementing them. Taxonomists are familiar with the peculiarities and structures of communities of taxonomic practice and the ways in which listing processes could be attuned to existing structures. Users of taxonomy can validly influence these criteria of adequacy - given that the right checks and balances are in place - because the criteria directly determine which kinds of lists will be endorsed by the endorsement body. Hence, for users to trust these lists and use them, it is important that the lists meet criteria that are important to the users. For example, international organizations would be unlikely to uniformly adopt lists that only take into account the taxonomic opinions of a small and biased subsection of relevant expertise and are highly controversial as a consequence. Finally, the expertise of specialists in governance, conflict resolution, and decision-making is crucial in designing criteria that are likely to work smoothly. This also applies to dispute resolution, for example in the situation where two competing lists are submitted that both meet the criteria of adequacy.
Together, the basic principles of the global listing process and the criteria of adequacy (as well as how these are decided, documented, implemented, and changed) make up the governance structure of the endorsement body. In the remainder of the paper, we will therefore refer to these as the 'endorsementlevel governance structure'.

The endorsement-level governance structure should be distinguished from a third governance component that requires value-laden decisions, namely, that of the particular taxonomic communities responsible for particular species lists. Each of these taxonomic communities is responsible for designing its own governance structure in line with the basic principles and criteria of adequacy. These community-level governance structures are likely to differ between different taxonomic communities, depending on such factors as already existing governance structures, the number of specialists willing and able to contribute, and available funding. As is the case for endorsement-level governance structures, taxonomic grounds do not determine which fine-grained governance mechanisms a particular listing process should use. Decisions concerning these mechanisms thus have to be made by the taxonomists on value-laden grounds. These taxonomists may of course consult experts in decision-making, conflict-resolution, or other relevant fields. However, users of taxonomy should not interfere with these decisions. For example, the criteria for accepting species on a list for a particular taxonomic community would need to be developed independently of users. Such influence would breach the principle of independence. Users' influence on the governance process should be limited to decisions about endorsement-level governance.

\section{Values in the global listing process: conclusions}

Having listed the three main roles values have to play in the global listing process, it is worth emphasizing that most decisions in a global listing process require no obvious value judgments. These decisions are easiest to define negatively: any decision not included in one of the three types discussed above should be made purely on taxonomic grounds. These decisions are the domain of taxonomists and should not be influenced by users of taxonomy. While these decisions are too many and varied to list exhaustively in the way the value-laden decisions were, they can broadly be said to encompass taxonomic research. This means that taxonomic research falls fully outside the scope of influence of the users of taxonomy, and retains its freedom and independence. ${ }^{5}$

\footnotetext{
${ }^{5}$ Of course, users may still influence taxonomic research by the way they distribute research funding, or by prioritizing conservation or funding for groups at particular ranks. In addition, there are of course many taxonomists who are also involved in regulation and policy. However, such influences are hard to avoid and independent from the way a global listing process is set up.
} 
One way of summarizing the contents of this section is that users should never be directly involved in decisions about which species to include on accepted species lists. That is, a species should never be listed, or excluded from listing, just because that is in the interest of one of its users. Whenever that happens, the independence principle has been breached. However, users can have indirect influence by setting evidentiary standards and contributing to the design of the governance mechanisms. It is important to be careful that these indirect influences cannot be abused to exert direct control over the content of species lists. For example, when evidentiary standards for inclusion of a species are set unrealistically high, the indirect influence of setting these standards directly determines the content of the list (Steel \& Whyte, 2012). Similarly, listing processes should have adequate conflict-ofinterest provisions to ensure that taxonomic specialists do not also serve the interests of particular users.

\section{Making value-laden decisions}

The previous section established that value-laden considerations are required for some of the decisions in the global listing process, and that users of taxonomy should be involved in some of these decisions. This should not be taken to mean that any consideration whatsoever can legitimately influence

Box 2 Main steps in the global listing process

\begin{tabular}{|c|c|c|}
\hline Steps in the listing process & Taxonomists & Users \\
\hline 1. Taxonomic Research & $\begin{array}{l}\text { Describe, name, and classify groups } \\
\text { of organisms, and investigate the } \\
\text { relations between these groups. }\end{array}$ & No role \\
\hline 2. Compiling lists & \multicolumn{2}{|c|}{ Make decisions in a neutral and transparent manner } \\
\hline Dealing with uncertainty & $\begin{array}{l}\text { Take the consequences of error } \\
\text { into account. }\end{array}$ & $\begin{array}{l}\text { Inform taxonomists about the } \\
\text { consequences of error. } \\
\text { Suggest priorities for taxonomic } \\
\text { research }\end{array}$ \\
\hline Conceptual decisions & $\begin{array}{l}\text { Make decisions in a consistent and } \\
\text { conservative manner. }\end{array}$ & No role \\
\hline 3. Accepting lists & $\begin{array}{l}\text { Make decisions in a neutral and } \\
\text { transparent manner }\end{array}$ & $\begin{array}{l}\text { Communicate preferences to } \\
\text { endorsement-body }\end{array}$ \\
\hline Taxon-specific lists & $\begin{array}{l}\text { Design of community-level } \\
\text { governance structure }\end{array}$ & No role \\
\hline Global consensus list & $\begin{array}{l}\text { Design of endorsement-level } \\
\text { governance structure } \\
\text { Evaluation of listing processes. }\end{array}$ & $\begin{array}{l}\text { Feedback and advice on } \\
\text { endorsement-level governance } \\
\text { structure without decision- } \\
\text { making. } \\
\text { Access to evaluation of listing } \\
\text { processes }\end{array}$ \\
\hline 4. Using lists & $\begin{array}{l}\text { Use of taxonomic data is consistent; } \\
\text { no more misunderstandings about, } \\
\text { for example, species richness due to } \\
\text { use of different and differing lists. }\end{array}$ & $\begin{array}{l}\text { Users endorse or adopt (parts of) } \\
\text { the accepted list, implement in } \\
\text { policy, or use in research. }\end{array}$ \\
\hline
\end{tabular}


the decisions that are not fully determined on taxonomic grounds, or that users can play any role whatsoever in making these decisions. The aim of this section is to describe on what grounds and by whom underdetermined decisions should be made. We do this by first describing the general principles that should guide value-laden decisions, and then by returning to the three types of value-laden decision discussed in the previous section. Box 2 summarizes this by providing an overview of the global listing process and the various roles of users and taxonomists in each step of the process.

\section{General principles}

Most broadly, we propose that value-laden decisions in the global listing process should be guided by two principles: neutrality and transparency.

According to the principle of neutrality, value-laden decisions in the global listing process should be made in a way that does not promote the interests of one particular user of the list over the interest of other users. Instead, neutral decisions should aim for the highest common denominator of the relevant value spectrum such that they are compatible with the preferences of all or most users. For example, the principle of neutrality implies that the criteria of adequacy for listing processes should be such that they are acceptable to all main users and sufficient for these users to trust the lists generated by these processes.

One implication of the principle of neutrality is that valueladen decisions are likely to be suboptimal for some users, even if they are acceptable for all. One may argue that this way, we miss the opportunity to attune species lists - within the boundaries of what is determined by purely taxonomic considerations - to things we value strongly, such as biodiversity conservation or effective and efficient conservation legislation. However, we argue that in the case of a global list, neutrality is a better course to take than such optimization of the list to certain highly valued outcomes. One reason is that the consequences of decisions in the listing process are very difficult to predict. This makes it difficult to base decisions in the listing process on potential outcomes. For example, even if everyone agreed that all value-laden decisions should be made in a way that promotes biodiversity conservation, it is far from clear which course of action would be best: both over-splitting and over-lumping can help or hinder conservation (Frankham et al., 2012). A second reason is that the success of a global list of accepted species depends strongly on global uptake of the list by the scientific community, governments, and nongovernmental organizations. Prioritization of the interests of certain users over others - that is, violations of neutralitywould make this unlikely.

Another implication of the principle of neutrality is that it is important to consult as broad a range of users and taxonomists as possible (see Box 1). ${ }^{6}$ This is because the needs of many smaller stakeholders are often not obvious and can remain invisible to those who are used to working with more prominent stakeholders in the listing process such as the managers of Multilateral Environmental Agreements (MEAs). Consulting a broad range of points of view makes it more likely that decisions are truly neutral, and does not violate needs or preferences that were simply not considered (Longino, 1990). Of course, this does not mean that the input of all stakeholders should have equal weight. The needs of a single user should not have the same weight as, for example, those of MEAs or databases that have broad societal impact.

The principle of neutrality should be coupled to transparency concerning value-laden decisions. In this context, transparency implies that all value-laden decisions, and the grounds for these decisions, are recorded and openly accessible. For example, this paper, Garnett et al. (2020), and the openly accessible report of the workshop on a global species list give an overview of the main principles for a global list as well as the reasons for adopting these particular principles. Such transparency is important for three reasons. First, it makes it possible to monitor value-laden decisions and their grounds, and, thus, to check whether value judgments played a role beyond the legitimate ones described in this paper. For example, lists could communicate uncertainty and disagreement about the taxa they list as species (Pyle et al., 2021). Second, transparency concerning these decisions is important for the perceived legitimacy of the list and the trust that potential users have in it. These, in turn, are necessary for the list to be taken up globally. For example, international organizations and agreements like the MEAs are unlikely to take up a consensus list unless it can be assured that it is not subject to undue influences. Finally, transparency concerning the grounds for particular decisions may be important when these decisions in the end turn out to have unwanted consequences for particular users. If in such cases it is clear that the grounds for these decisions were neutral, legitimate, and generally agreed on (particularly when these users were also consulted), these users are less likely to lose trust and refuse participation.

\section{Operationalizing neutrality}

The principle of neutrality applies in different ways to the two main groups of parties involved (users and taxonomists) and the three types of value-laden decisions in the global listing process. This subsection briefly elaborates on how this is the case.

\footnotetext{
${ }^{6}$ For example, neutrality could be achieved through a consensus-building model along with a method for assessing the level of consensus.
} 


\section{Users of taxonomy}

The main influence of users of taxonomy on the global listing process should be through consultation and feedback throughout the process of setting up the global listing process and its governance mechanisms. Such consultation should include both asking for input before establishing processes, and asking for feedback at various stages of implementation. As feedback and consultation are in no way binding, users of taxonomy need not be neutral and can clearly communicate their needs and preferences.

Importantly, users' opinions should never be sought by the taxonomic communities that compile the particular species lists to be accepted. This makes sure that users cannot directly influence which taxa get accepted or rejected. There is only one exception to this: taxonomic communities compiling species lists can choose to consult users when evaluating the costs of taxonomic error in cases of high uncertainty or substantial subjective disagreement, and when choosing evidentiary standards appropriate for including or excluding a taxon. On the basis of users' input, taxonomists can decide whether new research is needed before species can be included on or excluded from the list, or if the cost of error one way or the other is so low that existing evidence is sufficient. Conversely, which is probably more common in practice, users could identify important gaps in the literature or evidence, alert taxonomists about the costs of error, and request or commission taxonomic research to fill this gap.

In addition to consultation and feedback, the users of taxonomy should be involved in the global listing process through its evaluation. More precisely, users of taxonomy should at all times have access to information that shows the extent to which the criteria of adequacy and the rules of procedure are taken up by taxonomic communities or enforced by the endorsement body. This is crucial to maintain the trust of users in the global list.

\section{Taxonomists}

In the first place, taxonomists are responsible for all decisions that can be made on purely taxonomic grounds - most importantly, creating the species lists. In addition, taxonomists should also be involved in the three kinds of value-laden decisions.

First, taxonomists should make value-laden decisions concerning the governance structures on the basis of their own expertise and experience, the advice of non-taxonomic experts, and the information and feedback provided by the users of taxonomy. In doing so, they should aim to make their decisions such that they are acceptable to all or most stakeholders. In addition to the principle of neutrality, their decisions can be guided by the main principles (Garnett et al., 2020). For example, any preferences of users that clearly violate these principles can be disregarded without thereby violating the principle of neutrality. And whenever there are multiple viable options, these principles can help in selecting the best one.

Taxonomists should make decisions concerning uncertainty on the basis of their own expertise about the potential implications of error in listing or rejecting a taxon, but should not do this to promote a particular outcome. For example, taxonomists involved in compiling a particular species list can choose to impose stricter evidentiary requirements if the status of a species is very unclear and their decision is likely to have great economic impact. However, they should not demand more evidence merely to postpone a decision and avoid the omission of a particular species for, say, conservation reasons.

The trickiest are cases in which there is no fact of the matter to decide how broadly or narrowly to delimit a species. When a lineage is in the grey zone of evolutionary independence, this decision sometimes depends solely on conceptual decisions. This means that the decision of whether to delimit broadly or narrowly cannot simply be settled by collecting more empirical evidence. As already stated above, such decisions should be the sole responsibility of the taxonomic communities responsible for compiling the accepted species list of that group. Thus, even though these are value-laden decisions, users of taxonomy should not be allowed to influence them. The fact that these are value-laden decisions also should not be taken to imply that any value judgments whatsoever can be relied on to make such decisions. Of course, taxonomists do not work in a vacuum from society so are as susceptible as other citizens to extra-scientific interests in motivations. Nevertheless, we argue that in these decisions, they should consciously strive not to let such value-judgements play a role. We propose two neutral standards to rely on instead, namely, consistency and conservatism. Thus, whenever there is no fact of the matter as to whether to accept or reject a particular delimitation, then:

(a) The list should aim to maximize consistency with those of other groups of the same taxon (e.g. genus or family). For example, if most of the species in that taxon are recognized on the basis of the same set of criteria, then it is recommended that the same criteria are used here as well. ${ }^{7}$

(b) If a species is well-established and widely recognized by a large part of the relevant taxonomic community, then the species list should follow this usage.

These two standards should be used with care. For example, many traditional taxonomic decisions currently in use would not pass modern criteria. The risk of (b) then is that

\footnotetext{
${ }_{7}^{7}$ For a similar idea from within the taxonomic practice, see Taylor et al., 2017 and Tobias et al., 2010 and Principle 6 in (Garnett et al., 2020): 'The set of criteria considered sufficient to recognize species boundaries may appropriately vary between different taxonomic groups but should be consistent when possible'.
} 
these traditional views are chosen over newer views if the latter do not meet the often stricter criteria in use today. Thus, it is important to set the bar equally high for wellestablished views and competing views. In addition, these two norms are still inevitably vague, and are unlikely to resolve all value-laden decisions of this kind. However, they may serve as a basis for taxonomic communities to design mechanisms for resolving disagreements. For example, a taxonomic community that uses a voting system to choose which criteria or concept for species delimitation to use (arguably a decision for which there is no fact of the matter), would act in line with both these standards.

\section{How inclusion and independence are compatible}

Building on the discussion in the previous sections, we can now show how Principle 1 (taxonomy should be independent from non-taxonomic considerations) and Principle 2 (a global list of species should take into account the needs of its users) are compatible.

Consider first how the global listing process as we propose it is compatible with the independence of species lists. Most importantly, the notion of independence used here requires that every decision that can be settled completely on purely taxonomic grounds should also be settled in that way.

However, there are many decisions that are and cannot readily be determined using available, purely taxonomic, considerations. It is in making those decisions that users of the list can play a role. We consider a consensus list of the world's accepted species independent if, through their role in those decisions, the users of that list have at most an indirect influence on that list. 'Indirect' here means that their role is limited to influencing the endorsement-level governance structure of the list and evidentiary standards for listing. Important here is that none of these indirect influences concerns decisions about what status a group of organisms should have. Those decisions should always be the sole responsibility of taxonomists.

In addition to this restriction on the role users can play, there are also restrictions on the way they should play this role. Most importantly, users of the list should only influence these decisions through consultation, feedback, and evaluation. They should never be involved in decision-making itself, which should be based on users' input but is the sole responsibility of the endorsement body and the taxonomic communities involved in constructing species lists.

In short, we understand 'independence' as the requirement that users are only involved in decisions that are not determined on purely taxonomic grounds and that this involvement is limited to decisions about uncertainty and governance.
If we understand independence in this way, then it is fully compatible with involving users of taxonomy in the global listing process. This involvement consists of consulting users of taxonomy throughout the process of setting up the governance structure of the global lists. More precisely, their opinions and advice should be sought on the principles of the list, and the criteria of adequacy for listing processes. Drafts of these principles and criteria as well as more fine-grained rules of procedures and terms of reference should be sent to these users for feedback at as many stages of the drafting process as possible. One crucial function of the governance structure we propose to introduce, then, is to act as an interface for communication between taxonomists and list users.

In addition, taxonomic communities involved in listing can seek the advice of users when they set evidentiary standards for listing. This way, they can decide which groups to list or reject based on the currently available evidence, and set priorities for further research if listing or rejecting particular groups has major implications. Finally, users of taxonomy should have access to information about how and whether the particular listing processes are in line with the criteria of adequacy and how this is evaluated and enforced by the endorsement body.

By understanding independence and stakeholder involvement in this way, the list of the world's species can reflect the best available science without unwarranted influences from non-taxonomic considerations and at the same time ensure participation of stakeholders by involving them in the global listing process.

\section{Challenges for implementation}

So far, we have set out the roles of taxonomists and list users in very general terms, referring to equally general principles. To conclude the paper, this section discusses several challenges relating to inclusion and independence that have to be met in order to apply this abstract conceptual scheme.

\section{Values and taxonomic grounds: a complex mix}

Throughout the paper, we have attempted to draw clear boundaries between decisions concerning uncertainty, conceptual decisions, and purely taxonomic decisions. We argued that value judgements can only play a role in the former two and that list users can only play a role in the first of these. However, in practice, all three kinds of decisions are often closely intertwined, making it difficult to restrict the roles of value judgments, taxonomists, and users to their proper domains. For example, in the case of the California gnatcatcher, conceptual decisions, evaluation of the consequences of error, and competing conservation interests and financial interests are all entangled. Nevertheless, we think the division of labour as set out in 
Box 2 can be useful even if it provides little direct guidance in such complex cases. At a minimum, it spells out which kinds of considerations should and should not be taken into account. In addition, a clear conceptual picture of these roles is useful for this governance project because it shows that both users and taxonomists have an important role to play in a global listing process, and that they can do this without violating the principle of independence.

\section{Irresolvable taxonomic disagreement}

For some groups, like birds, there are longstanding taxonomic disagreements, where each of multiple competing lists has the support of a substantial part of the relevant community. These disagreements are often a complex mixture of issues (see previous paragraph), and it would be naive to think that general principles like 'consistency' and 'conservatism' will easily resolve them. Ultimately, a solution for such disagreements - for example, a single, widely accepted list for birds - can only come from the relevant communities, and we hope that formal governance mechanisms within these communities (designed and implemented by the communities themselves) can facilitate this. In fact, there already are attempts within the ornithological communities to reduce disagreement between their lists. The principles discussed in this paper only provide a general picture of how to make such value-laden, conceptual decisions without relying on extra-taxonomic considerations.

\section{Motivating list users and building trust}

The success of a global consensus list relies crucially on it being used and endorsed by as many important list users as possible, particularly international organizations and conventions such as the International Union for Conservation of Nature (IUCN), the Convention on International Trade in Endangered Species of Wild Fauna and Flora (CITES), and the Convention on the Conservation of Migratory Species of Wild Animals (CMS). This is a particularly complex problem, as it is likely that most important users would only be willing to adopt and endorse a list that is already well-established and used by other important users. In addition, the procedures that such conventions and organizations use for changing something as impactful as a species list are typically slow and complex to navigate. This means that uptake of a global consensus list, or parts of it (as a consensus list will not be available for all taxa at the same time), will at best be slow. All this means that it is crucial that these important users are involved early on in the design of endorsement-level governance mechanisms, and that these mechanisms address the needs of these users.

\section{Motivating taxonomists to participate}

Equally, the success of a global consensus list relies crucially on the willingness of taxonomists to participate in list governance. In an already crowded landscape of global lists and inventories of biodiversity, and with many other demands on their time, it may be difficult to motivate taxonomists to invest additional time and effort in an additional governance structure. Crucial here are recognition mechanisms for the effort taxonomists put in. Such mechanisms could include a formal citation of the lists that includes the editors' names as well as periodic publication of revised sections of lists in open-access journals. Another way to motivate taxonomists is to make sure that the consensus list also meets taxonomists' needs. This paper may also contribute if it persuades taxonomists to participate by showing that a restricted but important role for list users in the global listing process leaves the freedom of taxonomic research unaffected, and is compatible with a list based on the best science (Raposo et al., 2017; Thomson et al., 2018).

\section{Conclusion}

The role that users of taxonomy play in compiling taxonomic lists has recently shown to be a controversial topic (Raposo et al., 2017; Thomson et al., 2018). It is therefore crucial for a global listing process to face it head on and develop a framework to handle the apparent tension between independence and inclusion. This paper has proposed such a framework. More precisely, we have spelled out the kinds of roles that users can play in the global listing process so as to ensure inclusion without breaching the principle of independence. However, the tension between inclusion and independence is complex and tricky, and we do not expect this paper to resolve it. Instead, we hope that the framework introduced here can serve as a starting point for further discussion about these issues.

Acknowledgements This paper is one of a series published by the IUBS Working Group on the Governance of Taxonomic Lists. We are grateful for funding and support from the International Union of Biological Sciences and its Executive Officer Nathalie Fomproix, and administration of the grant by Roanne Ramsey (Charles Darwin University). Stijn Conix gratefully acknowledges funding from the Research Council Flanders (FWO; Grant 3H200026).

Code availability NA.

Author contribution All authors contributed to the paper's conception and design. The first draft of the manuscript was written by Stijn Conix and all authors commented on previous versions of the manuscript. All authors read and approved the final manuscript. 
Data availability Data sharing is not applicable to this article as no datasets were generated or analyzed during the current study.

\section{Declarations}

Competing interests The authors declare no competing interests.

\section{References}

Buckeridge, J. S., Beu, A. G., \& Gordon, D. P. (2018). Depositional environment of the early Pleistocene Castlepoint Formation, New Zealand: A canyon fill in situ. New Zealand Journal of Geology and Geophysics, 61(4), 524-542. https://doi.org/10.1080/00288306. 2018.1516227.

Bull, A. T., Ward, A. C., \& Goodfellow, M. (2000). Search and discovery strategies for biotechnology: The paradigm shift. Microbiology and Molecular Biology Reviews, 64(3), 573-606. https://doi.org/10. 1128/MMBR.64.3.573-606.2000.

Conix, S. (2018). Radical pluralism, classificatory norms and the legitimacy of species classifications. Studies in History and Philosophy of Science Part C: Studies in History and Philosophy of Biological and Biomedical Sciences, 73, 27-43. https://doi.org/10.1016/j.shpsc. 2018.11.002.

Costello, M. J. (2020). Taxonomy as the key to life. Megataxa, 1(2), 105113. https://doi.org/10.11646/megataxa.1.2.1.

Costello, M. J., May, R. M., \& Stork, N. E. (2013). Can we name earth's species before they go extinct? Science, 339(6118), 413-416. https://doi.org/10.1126/science.1230318.

De Queiroz, K. (2005). Different species problems and their resolution. BioEssays, 27(12), 1263-1269. https://doi.org/10.1002/bies.20325.

Dias, D. A., Urban, S., \& Roessner, U. (2012). A historical overview of natural products in drug discovery. Metabolites, 2(2), 303-336. https://doi.org/10.3390/metabo2020303.

Diniz-Filho, J. A. F., Loyola, R. D., Raia, P., Mooers, A. O., \& Bini, L. M. (2013). Darwinian shortfalls in biodiversity conservation. Trends in Ecology \& Evolution, 28(12), 689-695. https://doi.org/10.1016/j. tree.2013.09.003.

Douglas, H. (2000). Inductive risk and values in science. Philosophy of Science, 67(4), 559-579.

Douglas, H. (2009). Science, Policy, and the Value-Free Ideal. University of Pittsburgh Press.

Frankham, R., Ballou, J. D., Dudash, M. R., Eldridge, M. D. B., Fenster, C. B., Lacy, R. C., Mendelson III, J. R., Porton, I. J., Ralls, K., \& Ryder, O. A. (2012). Implications of different species concepts for conserving biodiversity. Biological Conservation, 153, 25-31. https://doi.org/10.1016/j.biocon.2012.04.034.

Garnett, S. T., \& Christidis, L. (2017). Taxonomy anarchy hampers conservation. Nature, 546(7656), 25-27. https://doi.org/10.1038/ 546025a.

Garnett, S. T., Christidis, L., Conix, S., Costello, M. J., Zachos, F. E., Bánki, O. S., Bao, Y., Barik, S. K., Buckeridge, J. S., Hobern, D., Lien, A., Montgomery, N., Nikolaeva, S., Pyle, R. L., Thomson, S. A., van Dijk, P. P., Whalen, A., Zhang, Z. Q., \& Thiele, K. R. (2020). Principles for creating a single authoritative list of the world's species. PLoS Biology, 18(7), e3000736. https://doi.org/ 10.1371/journal.pbio.3000736.

GBIF Secretariat. (2019). GBIF backbone taxonomy. Checklist dataset. $10.15468 / 39$ ome

Guston, D. H. (2001). Boundary organizations in environmental policy and science: An introduction. Science, Technology \& Human Values, 26(4), 399-408.
Harris, J., \& Froufe, E. (2005). Taxonomic inflation: Species concept or historical geopolitical bias? Trends in Ecology \& Evolution, 20(1), 6-7. https://doi.org/10.1016/j.tree.2004.11.004.

Harvey, A. L. (2008). Natural products in drug discovery. Drug Discovery Today, 13(19), 894-901. https://doi.org/10.1016/j. drudis.2008.07.004.

Hickling, R., Roy, D. B., Hill, J. K., Fox, R., \& Thomas, C. D. (2006). The distributions of a wide range of taxonomic groups are expanding polewards. Global Change Biology, 12(3), 450-455. https://doi.org/10.1111/j.1365-2486.2006.01116.x.

Hulme, M., \& Mahony, M. (2010). Climate change: What do we know about the IPCC? Progress in Physical Geography: Earth and Environment, 34(5), 705-718. https://doi.org/10.1177/ 0309133310373719

Isaac, N. J. B., Mallet, J., \& Mace, G. M. (2004). Taxonomic inflation: Its influence on macroecology and conservation. Trends in Ecology \& Evolution, 19(9), 464-469. https://doi.org/10.1016/j.tree.2004.06. 004.

John, S. (2015). The example of the IPCC does not vindicate the Value Free Ideal: A reply to Gregor Betz. European Journal for Philosophy of Science, 5(1), 1-13. https://doi.org/10.1007/s13194014-0095-4.

Karl, S. A., \& Bowen, B. W. (1999). Evolutionary significant units versus geopolitical taxonomy: Molecular systematics of an endangered sea turtle (genus Chelonia). Conservation Biology, 13(5), 990-999. https://doi.org/10.1046/j.1523-1739.1999.97352.x.

Kottelat, M. (1997). European freshwater fishes. An heuristic checklist of the freshwater fishes of Europe (exclusive of former USSR), with an introduction for non-systematists and comments on nomenclature and conservation. Biologia (Bratislava), 52(5), 1-271.

Lien, A., Christidis, L., Conix, S., Costello, M. J., Zachos, F. E., Bánki, O. S., et al. (2021). Towards a universal list of accepted species: a governance framework. https://doi.org/10.1007/s13127-021-00499-8.

Longino, H. E. (1990). Science as social knowledge: Values and objectivity in scientific inquiry. Princeton University Press.

Mace, G. M. (2004). The role of taxonomy in species conservation. Philosophical Transactions of the Royal Society of London. Series B: Biological Sciences, 359(1444), 711-719. https://doi.org/10. 1098/rstb.2003.1454.

Miller, C. (2001). Hybrid management: Boundary organizations, science policy, and environmental governance in the climate regime. Science, Technology \& Human Values, 26(4), 478-500. https:// doi.org/10.1177/016224390102600405.

Pyle, R. L., Christidis, L., Conix, S., Costello, M. J., Zachos, F. E., Bánki, O. S., et al. (2021). Towards a universal list of accepted species V. The devil is in the detail.

Raposo, M. A., Stopiglia, R., Brito, G. R. R., Bockmann, F. A., Kirwan, G. M., Gayon, J., \& Dubois, A. (2017). What really hampers taxonomy and conservation? A riposte to Garnett and Christidis (2017). Zootaxa, 4317(1), 179-184. https://doi.org/10.11646/zootaxa.4317. 1.10 .

Rooney, P. (1992). On values in science: Is the epistemic/non-epistemic distinction useful? PSA: Proceedings of the Biennial Meeting of the Philosophy of Science Association, 1992, 13-22.

Root, T. L., Price, J. T., Hall, K. R., Schneider, S. H., Rosenzweig, C., \& Pounds, J. A. (2003). Fingerprints of global warming on wild animals and plants. Nature, 421(6918), 57-60. https://doi.org/10.1038/ nature 01333

Rothman, D. S., van Bers, C., Bakkes, J., \& Pahl-Wostl, C. (2009). How to make global assessments more effective: Lessons from the assessment community. Current Opinion in Environmental Sustainability, 1(2), 214-218. https://doi.org/10.1016/j.cosust.2009.09.002.

Schlick-Steiner, B. C., Steiner, F. M., Seifert, B., Stauffer, C., Christian, E., \& Crozier, R. H. (2010). Integrative taxonomy: A multisource approach to exploring biodiversity. Annual Review of Entomology, 
55(1), 421-438. https://doi.org/10.1146/annurev-ento-112408085432.

Senn, H., Banfield, L., Wacher, T., Newby, J., Rabeil, T., Kaden, J., Kitchener, A. C., Abaigar, T., Silva, T. L., Maunder, M., \& Ogden, R. (2014). Splitting or Lumping? A Conservation Dilemma Exemplified by the Critically Endangered Dama Gazelle (Nanger dama). PLoS One, 9(6), e98693. https://doi.org/10.1371/ journal.pone.0098693.

Steel, D., \& Whyte, K. P. (2012). Environmental justice, values, and scientific expertise. Kennedy Institute of Ethics Journal, 22(2), 163-182. https://doi.org/10.1353/ken.2012.0010.

Steele, K. (2012). The scientist qua policy advisor makes value judgments. Philosophy of Science, 79(5), 893-904. https://doi.org/10. 1086/667842.

Taylor, B. L., Archer, F. I., Martien, K. K., Rosel, P. E., Hancock-Hanser, B. L., Lang, A. R., Leslie, M. S., Mesnick, S. L., Morin, P. A., Pease, V. L., Perrin, W. F., Robertson, K. M., Parsons, K. M., Viricel, A., Vollmer, N. L., Cipriano, F., Reeves, R. R., Krützen, M., \& Baker, C. S. (2017). Guidelines and quantitative standards to improve consistency in cetacean subspecies and species delimitation relying on molecular genetic data. Marine Mammal Science, 33(S1), 132-155. https://doi.org/10.1111/mms.12411.

Thiele, K., Christidis, L., Conix, S., Costello, M. J., Zachos, F. E., Bánki, O. S., et al. (n.d.). Taxonomy as map-making: The foundation for lists of accepted species.

Thomson, S. A., Pyle, R. L., Ahyong, S. T., Alonso-Zarazaga, M., Ammirati, J., Araya, J. F., Ascher, J. S., Audisio, T. L., AzevedoSantos, V. M., Bailly, N., Baker, W. J., Balke, M., Barclay, M. V. L., Barrett, R. L., Benine, R. C., Bickerstaff, J. R. M., Bouchard, P., Bour, R., Bourgoin, T., Boyko, C. B., Breure, A. S. H., Brothers, D. J., Byng, J. W., Campbell, D., Ceríaco, L. M. P., Cernák, I., Cerretti, P., Chang, C. H., Cho, S., Copus, J. M., Costello, M. J., Cseh, A., Csuzdi, C., Culham, A., D'Elía, G., d'Udekem d'Acoz, C., Daneliya, M. E., Dekker, R., Dickinson, E. C., Dickinson, T. A., van Dijk, P. P., Dijkstra, K. D. B., Dima, B., Dmitriev, D. A., Duistermaat, L., Dumbacher, J. P., Eiserhardt, W. L., Ekrem, T., Evenhuis, N. L., Faille, A., Fernández-Triana, J. L., Fiesler, E., Fishbein, M., Fordham, B. G., Freitas, A. V. L., Friol, N. R., Fritz, U., Frøslev, T., Funk, V. A., Gaimari, S. D., Garbino, G. S. T., Garraffoni, A. R. S., Geml, J., Gill, A. C., Gray, A., Grazziotin, F. G., Greenslade, P., Gutiérrez, E. E., Harvey, M. S., Hazevoet, C. J., He, K., He, X., Helfer, S., Helgen, K. M., van Heteren, A. H., Hita Garcia, F., Holstein, N., Horváth, M. K., Hovenkamp, P. H., Hwang, W. S., Hyvönen, J., Islam, M. B., Iverson, J. B., Ivie, M. A., Jaafar, Z., Jackson, M. D., Jayat, J. P., Johnson, N. F., Kaiser, H., Klitgård, B. B., Knapp, D. G., Kojima, J. I., Kõljalg, U., Kontschán, J., Krell, F. T., Krisai-Greilhuber, I., Kullander, S., Latella, L.,
Lattke, J. E., Lencioni, V., Lewis, G. P., Lhano, M. G., Lujan, N. K., Luksenburg, J. A., Mariaux, J., Marinho-Filho, J., Marshall, C. J., Mate, J. F., McDonough, M. M., Michel, E., Miranda, V. F. O., Mitroiu, M. D., Molinari, J., Monks, S., Moore, A. J., Moratelli, R., Murányi, D., Nakano, T., Nikolaeva, S., Noyes, J., Ohl, M., Oleas, N. H., Orrell, T., Páll-Gergely, B., Pape, T., Papp, V., Parenti, L. R., Patterson, D., Pavlinov, I. Y., Pine, R. H., Poczai, P., Prado, J., Prathapan, D., Rabeler, R. K., Randall, J. E., Rheindt, F. E., Rhodin, A. G. J., Rodríguez, S. M., Rogers, D. C., Roque, F. . O., Rowe, K. C., Ruedas, L. A., Salazar-Bravo, J., Salvador, R. B., Sangster, G., Sarmiento, C. E., Schigel, D. S., Schmidt, S., Schueler, F. W., Segers, H., Snow, N., Souza-Dias, P. G. B., Stals, R., Stenroos, S., Stone, R. D., Sturm, C. F., Štys, P., Teta, P., Thomas, D. C., Timm, R. M., Tindall, B. J., Todd, J. A., Triebel, D., Valdecasas, A. G., Vizzini, A., Vorontsova, M. S., de Vos, J. M., Wagner, P., Watling, L., Weakley, A., Welter-Schultes, F., Whitmore, D., Wilding, N., Will, K., Williams, J., Wilson, K., Winston, J. E., Wüster, W., Yanega, D., Yeates, D. K., Zaher, H., Zhang, G., Zhang, Z. Q., \& Zhou, H. Z. (2018). Taxonomy based on science is necessary for global conservation. PLoS Biology, 16(3), e2005075. https://doi.org/10.1371/journal.pbio.2005075.

Tobias, J. A., Seddon, N., Spottiswoode, C. N., Pilgrim, J. D., Fishpool, L. D. C., \& Collar, N. J. (2010). Quantitative criteria for species delimitation. Ibis, 152(4), 724-746. https://doi.org/10.1111/j.1474919X.2010.01051.x.

Young, J. C., Waylen, K. A., Sarkki, S., Albon, S., Bainbridge, I., Balian, E., Davidson, J., Edwards, D., Fairley, R., Margerison, C., McCracken, D., Owen, R., Quine, C. P., Stewart-Roper, C., Thompson, D., Tinch, R., van den Hove, S., \& Watt, A. (2014). Improving the science-policy dialogue to meet the challenges of biodiversity conservation: having conversations rather than talking at one-another. Biodiversity and Conservation, 23(2), 387-404. https://doi.org/10.1007/s10531-013-0607-0.

Zachos, F. E. (2016). Species concepts in biology: Historical development, theoretical foundations and practical relevance. Springer.

Zachos, F. E., Christidis, L., \& Garnett, S. T. (2020). Mammalian species and the twofold nature of taxonomy: A comment on Taylor et al. 2019. Mammalia, 84(1), 1-5. https://doi.org/10.1515/mammalia2019-0009.

Zink, R. M., Barrowclough, G. F., Atwood, J. L., \& Blackwell-Rago, R. C. (2000). Genetics, taxonomy, and conservation of the threatened California gnatcatcher. Conservation Biology, 14(5), 1394-1405. https://doi.org/10.1046/j.1523-1739.2000.99082.x.

Publisher's note Springer Nature remains neutral with regard to jurisdictional claims in published maps and institutional affiliations. 